\title{
Beaucire F., Desjardins X., 2015, Notion d'urbanisme par l'usage, Paris, Publications de la Sorbonne, 120 pages.
}

\section{Guillaume Schmitt}

\section{OpenEdition}

\section{Journals}

Édition électronique

URL : https://journals.openedition.org/developpementdurable/11614

DOI : 10.4000/developpementdurable.11614

ISSN : 1772-9971

Éditeur

Association DD\&T

Référence électronique

Guillaume Schmitt, « Beaucire F., Desjardins X., 2015, Notion d'urbanisme par l'usage, Paris, Publications de la Sorbonne, 120 pages. ", Développement durable et territoires [En ligne], Vol. 8, n¹ | Avril 2017, mis en ligne le 30 avril 2017, consulté le 08 mars 2022. URL : http://journals.openedition.org/ developpementdurable/11614; DOI : https://doi.org/10.4000/developpementdurable.11614

Ce document a été généré automatiquement le 8 mars 2022

\section{(c) (7) (8)}

Développement Durable et Territoires est mis à disposition selon les termes de la licence Creative Commons Attribution - Pas d'Utilisation Commerciale 4.0 International. 
Beaucire F., Desjardins X., 2015, Notion d'urbanisme par l'usage, Paris, Publications de la Sorbonne, 120 pages.

\author{
Guillaume Schmitt
}

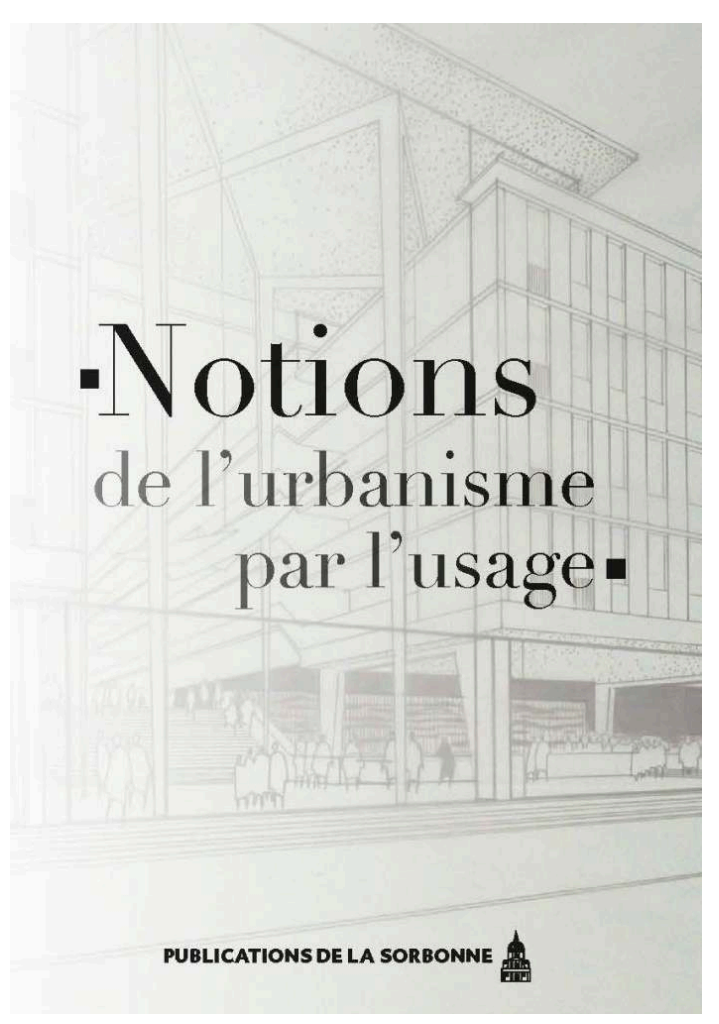

L'ouvrage "Notions de l'urbanisme par l'usage » confectionné par Francis Beaucire et Xavier Desjardins est original par bien des points. 
2 Par sa forme tout d'abord, avec 117 pages au format poche, les auteurs ont réussi à associer une vingtaine de notions sous l'égide de 7 notions " tête de grappe » (p. 15 centralité, milieu, densité, mixité, espace public, mobilité et urbanité) et une cinquantaine d'extraits de livres, d'articles ou de communications datant de 1860 à nos jours. D'emblée, le lecteur s'interroge sur les notions mises en avant, sont-elles vraiment les plus représentatives ou significatives du groupe qu'elles représentent? Pourquoi certaines notions qu'il est possible de considérer comme "importantes ", à l'instar du périurbain, sont-elles oubliées? Néanmoins, ces notions et textes sont encadrés par une introduction solide positionnant le livre par rapport aux anthologies ou aux dictionnaires et une conclusion sous forme de graphes relationnelles entre les notions permettant de faire des synthèses. Chaque chapitre comprend une brève présentation des notions (1 à 2 pages), des extraits de textes (entre 6 et 10 par chapitres) accompagnés d'une présentation de ces derniers par les auteurs de l'ouvrage.

3 Il est édité aux publications de la Sorbonne et a bénéficié de l'appui de la fondation Charles Léopold Meyer et plus précisément du projet CITEGO (cités, territoires, gouvernance) qui associe à la fois des personnes morales et des personnes physiques agissant en leur nom ou en celui de leur institution de rattachement. D'ailleurs, une part considérable, si ce n'est la totalité de l'ouvrage dans sa version première (sans doute) est consultable par bribes sur le site Internet de CITEGO. On notera d'ailleurs que les schémas initiaux et manuscrits du dernier chapitre y sont repris en couleur. Outre la forme, ils ne sont pas scrupuleusement identiques à la version papier. Les différences dans les relations entre les notions associées (les auteurs parlent de "grappe de notion » - p.15) invitent d'ailleurs à essayer de reconstituer le cheminement intellectuel des auteurs et les éventuelles scories de la reprographie. Dans la version numérique, « l'ambiance » a des «effets» sur «l'attractivité », tandis que dans la version papier, elle en est une « condition de » (p. 116).

4 Cet exemple souligne bien l'originalité première de l'ouvrage. Il est à plusieurs niveaux de lecture et invite à des réflexions sur les choix opérés en amont de sa réalisation, donne à lire une interprétation efficace de grandes notions de l'urbanisme, amène à relire les ouvrages classiques et à aller parfois vers la « vraie littérature » (p. 14) pour se délecter de description faisant fi des définitions académiques à l'instar de l'extrait du livre « Déclin et survie des grandes villes américaines » de Janes Jacobs (p. 84-85). Les choix des auteurs sont clairement expliqués dans l'introduction (entre l'enseignement de l'urbanisme, l'actualité scientifique et les pratiques professionnelles). Les notions sont âprement discutées à l'instar de la présentation des relations entre la densité, l'intensité la compacité des villes. Les extraits de texte témoignent des similitudes au cours du temps dans l'emploi des notions et parfois de contradictions entre auteurs.

5 Ainsi cet ouvrage peut être lu tout autant par des personnes sensibles aux questions de l'urbanisme, par des étudiants souhaitant disposer d'un aperçu disciplinaire au commencement de leur formation ou au contraire par des étudiants et des enseignants souhaitant disposer d'une rapide synthèse et d'un ouvrage amenant à relire et repenser les acquis académiques. Il s'agit finalement d'un ouvrage bien organisé donnant l'envie de relire ou découvrir la totalité des textes dont les auteurs se sont servis. 


\section{AUTEUR}

\section{GUILLAUME SCHMITT}

Guillaume Schmitt est maître de conférences en géographie à l'Université de Valenciennes et du Hainaut Cambrésis (ULNF, UVHC). Ses recherches portent sur la thématique foncière et la mobilisation des outils de connaissance et d'intervention dans la définition et le suivi des politiques publiques. 